\title{
Explaining the Geographic Pattern of Plant Invasion in 67 Nature Reserves in China
}

\author{
Shengbin Chen ${ }^{1}$, Zhiyang Chen ${ }^{1}$, Wenjie Huang ${ }^{1}$, Changliang Shao ${ }^{2 *}$, Lingfeng Mao ${ }^{3}$ \\ and Johan Willem Frederik Slik ${ }^{4}$ \\ ${ }^{1}$ College of Ecology and Environment, Chengdu University of Technology, Chengdu, China, ${ }^{2}$ Institute of Agricultural \\ Resources and Regional Planning, Chinese Academy of Agricultural Sciences (CAS), Beijing, China, ${ }^{3}$ Co-Innovation Center \\ for Sustainable Forestry in Southern China, College of Biology and the Environment, Nanjing Forestry University, Nanjing, \\ China, ${ }^{4}$ Environmental and Life Sciences, Faculty of Science, Universiti Brunei Darussalam, Gadong, Brunei
}

OPEN ACCESS

Edited by:

Junhua $\mathrm{Hu}$,

Chengdu Institute of Biology, Chinese Academy of Sciences (CAS), China

Reviewed by: Aiping Wu,

Hunan Agricultural University, China

Yongchuan Yang,

Chongqing University, China

*Correspondence:

Changliang Shao shaochangliang@caas.cn

Specialty section:

This article was submitted to

Conservation and Restoration Ecology,

a section of the journal

Frontiers in Ecology and Evolution

Received: 18 January 2021

Accepted: 16 August 2021

Published: 27 September 2021

Citation:

Chen S, Chen Z, Huang W,

Shao C, Mao L and Slik JWF (2021)

Explaining the Geographic Pattern

of Plant Invasion in 67 Nature

Reserves in China.

Front. Ecol. Evol. 9:655313.

doi: 10.3389/fevo.2021.655313
Biological invasion is a serious threat to biodiversity and ecosystem function in nature reserves. However, the knowledge of the spatial patterns and underlying mechanisms of plant invasions in nature reserves is still limited. Based on a recent dataset on both invasive and native plants in 67 nature reserves of China, we used correlation, regression, and variation partitioning methods to statistically assess the relative roles of the "human activity," "biotic acceptance," and "environmental heterogeneity" hypotheses in explaining the geographic pattern of plant invasion. A total of 235 invasive plant species were compiled from 67 nature reserves. The high explanatory power of the human activity variables supported the human activity hypothesis. The biotic acceptance hypothesis was weakly supported since no significant correlations between climatic variables and invasion levels were found when the effects of the other factors were controlled. The environmental heterogeneity hypothesis was partially supported, since the number of native plants, representing environmental heterogeneity at finescale explained remarkable proportion of spatial variance of invasive plants but not that of the proportion of invasive plants. We predict that nature reserves with high plant diversity affected by rapid economic development and increasing temperature will face a serious threat of exotic plant invasion. In conclusion, our results provide crucial clues for understanding geographic variance of plant invasion in China's nature reserves and spatial risk assessment.

Keywords: alien species, protected areas, human activity, biotic acceptance, habitat heterogeneity, climate change

\section{INTRODUCTION}

As an important component of global change, plant invasion has intensified with the rapid development of globalization (Roura-Pascual et al., 2021). Plant invasion can severely affect not only the fate of individual species and community structures (Pyšek et al., 2012; Foxcroft et al., 2017), but also some critical ecosystem functions (Parker et al., 1999; Pyšek et al., 2012), and finally lead to economic losses (Vilà et al., 2010; Pyšek et al., 2020). Understanding the mechanisms of plant invasion is crucial to prevent its negative ecological and economic losses.

Previous studies have reported that invasion level (the number or proportion of invasive species) is highly correlated with social-economic conditions, environmental variables, and native 
species diversity at regional scales (Lonsdale, 1999; Taylor and Irwin, 2004; Allen et al., 2009; Pyšek et al., 2010). Therefore, there are correspondingly three main hypotheses proposed to explain the geographical pattern of invasion: "human activity" (Taylor and Irwin, 2004; Blanchet et al., 2009; Catford et al., 2009, 2011), "biotic acceptance" (Fridley et al., 2007; Blanchet et al., 2009), and "environmental heterogeneity" (Melbourne et al., 2007; Enders et al., 2020). They, respectively, highlight the roles of anthropogenic pressure, environmental constraints, and local habitat heterogeneity. According to the recent consensus network on 39 common hypotheses in invasion biology, five main clusters (propagule, Darwin, resource availability, biotic interaction, and trait) were revealed by a link-clustering algorithm (Enders et al., 2020). These three hypotheses, human activity, biotic acceptance, and environmental heterogeneity, belong to the clusters of propagule, Darwin, and resource availability, respectively. This indicates the weak similarity and overlap among them (Enders et al., 2020; Pyšek et al., 2020). We don't consider the biotic resistance hypothesis because it generally works at local/community scales and has been frequently rejected at regional scales (Lonsdale, 1999; Beaury et al., 2020).

The human activity hypothesis predicts that human activities can augment the establishment possibility of non-native species by disturbing the local habitat and increasing propagule pressure (quantity, quality, composition, and supply rate of alien species) (Taylor and Irwin, 2004; Catford et al., 2009). Positive relationships can be expected between invasion level and the anthropogenic surrogates of propagule pressure and habitat disturbance (Taylor and Irwin, 2004). The biotic acceptance hypothesis focuses on environmental conditions and states that, at large spatial scales, the abiotic conditions that promote high native species diversity also support diverse alien species (Davies et al., 2005; Fridley et al., 2007). Everything else being equal, there should be a positive relationship between the number of native and invasive species because they co-vary with the same environmental variables (Davies et al., 2005; Stohlgren et al., 2006). The environmental heterogeneity hypothesis predicts that regions with higher heterogeneity in the local environment would harbor higher invasive levels because heterogeneous habitat provides more opportunities for the establishment of invasive species (Melbourne et al., 2007). Accordingly, there should be positive relationships between invasion level and various quantifications of environmental heterogeneity (Melbourne et al., 2007; Stein et al., 2014). These hypotheses are not necessarily mutually exclusive, and their relative roles may vary during the successive stages of biological invasion (initial dispersal, establishment, and spread) (Catford et al., 2009), across biogeographic realms (Blanchet et al., 2009; Catford et al., 2009), and among different invading taxa (Stohlgren et al., 2006; Pyšek et al., 2010; Spear et al., 2013). According to the consensus network on invasion hypotheses (Enders et al., 2018, 2020), human activity in this study mostly represents colonization pressure and propagule pressure other than local disturbance, since nature reserves are strictly managed to have a hard boundary from invasion (Foxcroft et al., 2017).
When testing these hypotheses, it's important to use different indices of invasion level, while paying attention to the interactions among different hypotheses. The invasion level is regarded as the extent or severity of observed biological invasion in an ecosystem (Chytr $r$ et al., 2008). At geographic scales, absolute invasive/alien species richness (number of invasive/alien species) has been frequently used to quantify invasion levels. However, its ability to reflect the impacts of invasion depends on the recipient ecosystem (Catford et al., 2012). Relative invasive/alien species richness, the proportion of all invasive/alien species, accounts for variation in native richness. Relative richness is better than absolute richness for comparing invasion levels among regions, in terms of ecological impact, scale dependence, and data availability (Catford et al., 2012; Bai et al., 2013). However, most previous tests were based on absolute richness, especially at regional scales. In addition, variables representing different hypotheses may interact with each other. For example, human activities are affected by environmental variables (Luck, 2007). Therefore, specific predictions should be formulated regarding absolute or relative richness, and the strength and magnitude of each hypothesis should be statistically explicitly evaluated.

Plant invasions have been observed in protected areas located in different ecoregions (e.g., Foxcroft et al., 2017). The mechanisms leading to spatial variation of invasion levels among protected areas are mostly attributed to human disturbance, regional climate, and native biota. Some studies found anthropogenic variables were significant predictors of invasive species richness in nature reserves, climactic variables were usually not (e.g., Spear et al., 2013), while others reported contrasting results (e.g., Gantchoff et al., 2018). This implies the necessity of research in ecoregions with different climate conditions, social-economic situations, and native biota.

In this study, the data on native and invasive plants from 67 nature reserves in China were compiled and used, focusing on the relative importance of human activity, biotic acceptance, and environmental heterogeneity hypotheses. The selected nature reserves cover a wide latitude from 18.6 to $51.4^{\circ} \mathrm{N}$, and a wide longitude from 83.0 to $128.9^{\circ} \mathrm{E}$. The dominant ecosystem in these nature reserves is forest ranging from tropical to temperate climates. The wide geographic coverage of the data makes it valuable for understanding geographic pattern of plant invasion in nature reserves and effective management.

\section{MATERIALS AND METHODS}

\section{Data Sources}

We compiled species lists of all seed plants (hereafter referred to plants) from the inventory reports of 67 nature reserves in China (Supplementary Material). The species names were standardized by The Plant List. ${ }^{1}$ Data on the area, coordinates (latitude and longitude), and topography (minimum and maximum elevation) of each nature reserve were also obtained from original publications. The status of each plant species was then

\footnotetext{
${ }^{1}$ http://www.theplantlist.org
} 
determined according to the most recent compilation of invasive plants in China (Bai et al., 2013). The numbers of native plants (NNP) and invasive plants (NIP) were counted according to the species list for each nature reserve. The relative invasive plant richness (RPR) in each nature reserve was calculated by dividing the number of invasive plants by the number of all plants (Catford et al., 2012).

\section{Putative Predictors}

We selected 11 variables to test our three hypotheses. For the human activity hypothesis, we used human population density (HPD), gross domestic product (GDP), GDP per unit area (GUA), and GDP per capita (GPC) in the counties/districts where the nature reserves were located (data in the year 2010 obtained from the yearbook of each county/district). For the biotic acceptance hypothesis, we emphasized climatic conditions and used mean annual temperature (TEM), mean annual precipitation (PRE), mean temperature of the coldest quarter (TCQ), and mean precipitation of the driest quarter (PDQ). For the environmental heterogeneity hypothesis, we used altitudinal range (ALR, maximum elevation - minimum elevation), area (ARE), and the numbers of native plants (NNP).

HPD, GDP, GUA, and GPC have been frequently considered as surrogates of anthropogenic pressure for plant invasions at regional scales (e.g., Liu et al., 2005; Allen et al., 2009; Pyšek et al., 2010; Wu et al., 2010). The climatic variables represent the factors controlling the physiological processes limiting the spatial distribution of invasive plants (Liu et al., 2005; Allen et al., 2009; Pyšek et al., 2010; Wu et al., 2010). ALR and ARE represent habitat heterogeneity at the local scale, which is frequently used in macroecological studies (e.g., Chen et al., 2011). NNP well represents heterogeneity at the fine-scale, since it's highly correlated with vegetation structure (Stein et al., 2014). Data for TEM, PRE, TCQ, and PDQ were obtained from WorldClim (Hijmans et al., 2005) according to the coordinates of the midpoint of each nature reserve.

\section{Data Analysis}

NNP, NIP, and all the environmental and human variables (except TEM, PRE, TCQ, and PDQ) were ln-transformed to compensate for their highly skewed distributions. RPR was arcsine transformed as $\arcsin \sqrt{x}$, which is suggested as an appropriate method to transform proportion data (Sokal and Rohlf, 1995).

We analyzed the form and the significance of the relationships between each variable related to one hypothesis and NIP or RPR, after controlling for the effect of the confounding variables. We did so because the putative predictors were highly correlated (the absolute value of Pearson's correlation coefficient ranging from 0.10 to 0.89 ). When testing the human activity hypothesis, we related HPD, GDP, GUA, and GPC with the residual of the models of NIP or RPR against TEM, PRE, TCQ, PDQ, NNP, ALR, and ARE. This allowed us to control for the effects of environmental variables, which are related to biotic acceptance and environmental heterogeneity hypotheses. When testing the biotic acceptance hypothesis, we analyzed the form and the significance of the relationship between TEM, PRE, TCQ, PDQ and the residuals from a model explaining NIP or RPR by HPD, GDP, GUA, GPC, NNP, ALR, and ARE. The effects of human activities and regional climate could be controlled in this way. Finally, when testing the environmental heterogeneity hypothesis, we analyzed the form and the significance of the relationships between the NNP, ALR, ARE and the residuals from a model explaining the NIP or RPR by HPD, GDP, GUA, GPC, TEM, PRE, TCQ, and PDQ. We used Spearman rank correlation to assess the relationships between independent variables and model residuals because the model residuals were not normally distributed.

We used hierarchical partitioning to assess the joint and independent effects of each variable on NIP and RPR. Hierarchical partitioning is an exploratory regression technique in which all possible linear models are jointly considered to identify the most likely explanatory factors while minimizing the influence of collinearity. This method allows the identification of the independent contribution of each variable and separates it from the joint contribution due to correlation among variables (Quinn and Keough, 2002). The package hier.part was used for hierarchical partitioning and associated randomization tests of significance.

Since there was significant spatial autocorrelation in the residuals of the OLS models, we used Dutilleul's modified $t$-test to determine the significance of the correlations based on corrected degrees of freedom (Rangel et al., 2010). Statistical analyses were mainly carried out using "Spatial Analysis in Macroecology" (Rangel et al., 2010).

\section{RESULTS}

A total of 235 invasive plant species were recorded in the 67 nature reserves. The number of invasive plants (NIP) in the 67 nature reserves varied from 1 to 129 , with a mean value of 30 . The proportion of invasive plants (RPR) varied from 0.4 to $6.8 \%$, with a mean of $2.4 \%$. Nature reserves in South and Southeast China were higher in NIP than those in the other regions, while RPR shows a less pronounced spatial pattern although nature reserves in Southeast China generally have higher RPR (Figure 1).

After controlling for the effect of environmental conditions, the variables to test the human activity hypothesis were found to be positively related to NIP (gross domestic product, GDP) and RPR (GDP and GDP per capita, GPC). After controlling for the effects of human activity and environmental heterogeneity, no positive correlations between NIP or RPR and biotic acceptance variables were found. After the effects of climatic conditions and human activity were controlled, the only significant correlation was found between NIP and the number of native plant species (NNP) (Table 1).

Hierarchical partitioning revealed significant independent effects of HPD, GUA, TEM, PRE, and NNP for NIP, with NNP having the strongest independent effect. While RPR, GUA, ARE, and TEM had significant independent effects (Figure 2). The environmental factors (TEM, PRE) and NNP had the greatest independent effect on NIP (83.8\%), while for RPR, the total independent effects of human activity variables $(32.3 \%)$ and 


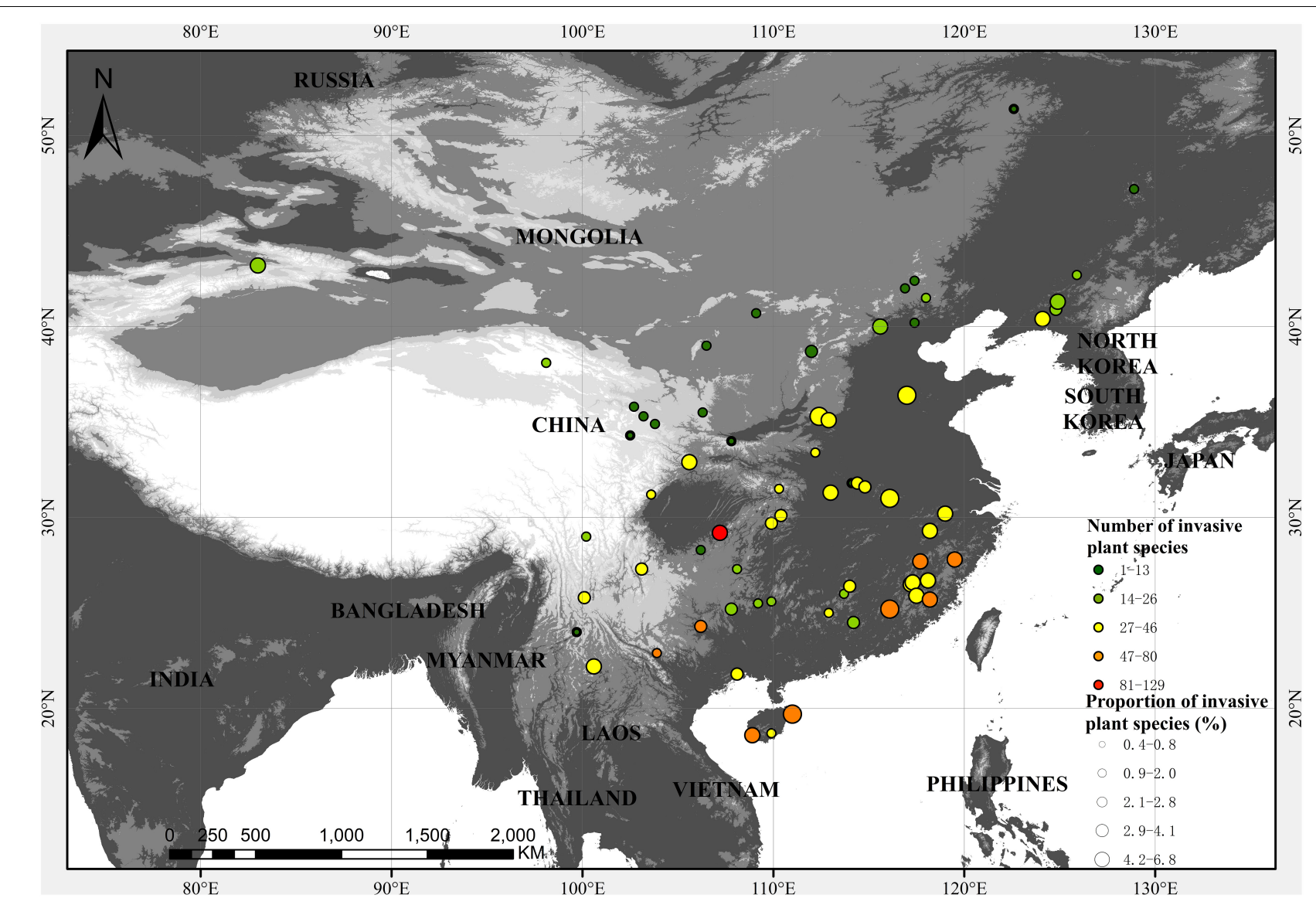

FIGURE 1 | Spatial distribution of the number (color) and proportion (size) of invasive plants in 67 nature reserves.

biotic reacceptance variables (37.7\%) were comparable. GUA and TEM had significant independent explanatory power for both NIP and RPR (Figure 2).

\section{DISCUSSION}

By correlation, regression, and variation partitioning analyses, we determined the relative roles of human activity, biotic acceptance, and environmental heterogeneity hypotheses in explaining geographic patterns of plant invasion levels in 67 China's nature reserves. The results showed that plant invasion level, represented by either the number or the proportion of invasive plant species, was positively related to human activity indicators. They accounted for a significant part of the geographic variation of invasion level, supporting the human activity hypothesis. The biotic acceptance hypothesis was weekly supported because climatic variables explained little of the variation of invasion level when the other effects were controlled. The evidence of the environmental heterogeneity hypothesis was ambiguous since the analytical results based on the number or the proportion of invasive plants were not identical.

The economic aspect of human activities can be well reflected by gross domestic product (GDP), GDP per unit area (GUA, and per capita GDP (GPC). All three factors had significantly positive effects on plant invasion levels in the nature reserves. This agrees with the results of recent analyses which highlight the potential of socioeconomic developments in shaping biological invasion (e.g., Pyšek et al., 2010; Dawson et al., 2017; RouraPascual et al., 2021). Pyšek et al. (2010) found national wealth and human population density were statistically significant predictors for biological invasions across Europe. This was reinforced by similar results from a global analysis, which concluded that regions with higher GPC harbor more alien species (Dawson et al., 2017). Furthermore, Essl et al. (2011) proposed that the effect of current socioeconomic activity on biological invasion will emerge in the future. This means that socioeconomic legacy yields an invasion debt. Recognizing the rapid socioeconomic development in China, our finding highlights the high risk of plant invasion in nature reserves.

When using the proportion of invasive plants as the indicator of invasion level in nature reserves, the importance of human activity was more pronounced than taking the number of invasive plants as invasion level. Because previous studies showed that relative invasive richness is more reasonable than absolute invasive richness (Bai et al., 2013), the studies based on absolute richness might underestimate the role of human activity in explaining spatial invasion patterns at regional scales. The 
TABLE 1 | Spearman rank correlation $\left(r_{s}\right)$ between the number and proportion of invasive plants and each predictive variable related to the human activity, biotic acceptance, and biotic resistance hypotheses $(n=67)$.

\begin{tabular}{|c|c|c|c|c|c|}
\hline \multirow[t]{2}{*}{ Hypothesis } & \multirow[t]{2}{*}{ Variable } & \multicolumn{2}{|c|}{ NIP } & \multicolumn{2}{|c|}{ RPR } \\
\hline & & $r_{s}$ & $p$ & $r_{s}$ & $p$ \\
\hline \multirow[t]{4}{*}{ Human activity hypothesis } & HPD & 0.145 & 0.184 & 0.147 & 0.280 \\
\hline & GDP & 0.317 & 0.045 & 0.293 & 0.035 \\
\hline & GUA & 0.295 & 0.058 & 0.317 & 0.060 \\
\hline & GPC & 0.293 & 0.051 & 0.345 & 0.018 \\
\hline \multirow{4}{*}{$\begin{array}{l}\text { Biotic acceptance } \\
\text { hypothesis }\end{array}$} & TEM & 0.073 & 0.801 & 0.224 & 0.153 \\
\hline & PRE & 0.029 & 0.833 & 0.202 & 0.184 \\
\hline & $\mathrm{TCQ}$ & 0.034 & 0.915 & 0.193 & 0.158 \\
\hline & PDQ & 0.036 & 0.657 & 0.194 & 0.212 \\
\hline \multirow{3}{*}{$\begin{array}{l}\text { Environmental } \\
\text { heterogeneity hypothesis }\end{array}$} & NNP & 0.376 & $<0.001$ & -0.031 & 0.981 \\
\hline & ALR & 0.233 & 0.207 & 0.036 & 0.986 \\
\hline & ARE & -0.097 & 0.478 & -0.180 & 0.267 \\
\hline
\end{tabular}

For each hypothesis, the relationship between the number and proportion of invasive plants and predictive variables considered was quantified by controlling for the effects of the predictive variables relevant to the other hypotheses (see section "Materials and Methods" for more details).

The $p$-values were calculated after accounting for spatial autocorrelation using Dutilleul's method. NIP, number of invasive plants; RPR, relative invasive plant richness; HPD, human population density; GDP, gross domestic product; GUA, GDP per unit area; GPC, Per capita GDP; NNP, number of native plants; ALR, altitudinal range; TEM, mean annual temperature; PRE, annual precipitation; ARE, area of nature reserve. Bold values are significant according to the $p$-values $<0.05$.

possibility and magnitude of changes in economic activities and human population are likely to be higher than climate change in the future. Therefore, much attention should be paid to human activity around protected areas to control plant invasion.

Our results explicitly show that the climatic factors in nature reserves are the main drivers of spatial variation in the number of invasive plants, supporting the biotic acceptance hypothesis (Stohlgren et al., 2006). However, when taking the proportion of invasive plants as an invasion level indicator, the ability of biotic acceptance hypothesis decreased remarkably. After the effects of human activity and environmental heterogeneity were controlled, no climatic variables were found to be significantly correlated with either the number or the proportion of invasive plant species. Therefore, the promotion effect of future global warming will be pronounced for the number of invasive plant species, and weak for the proportion of invasive plant species.

Other than large-scale climatic variables, native plants richness represents habitat heterogeneity at the fine-scale (which cannot be described by climatic variables). Variation partitioning analysis showed that native plant richness alone had a significant effect on the number of invasive plant species, but not for the proportion of invasive plant species. Therefore, the support for environmental heterogeneity hypothesis was not consistent.

Plant invasion has been recognized as a potential threat to the conservation of biodiversity in protected areas worldwide (Lonsdale, 1999; Spear et al., 2013; Foxcroft et al., 2017). It may erode the conservation capacity of nature reserves due to its detrimental effects on the native species and ecosystem processes (Vilà et al., 2010; Pyšek et al., 2012; Foxcroft et al.,

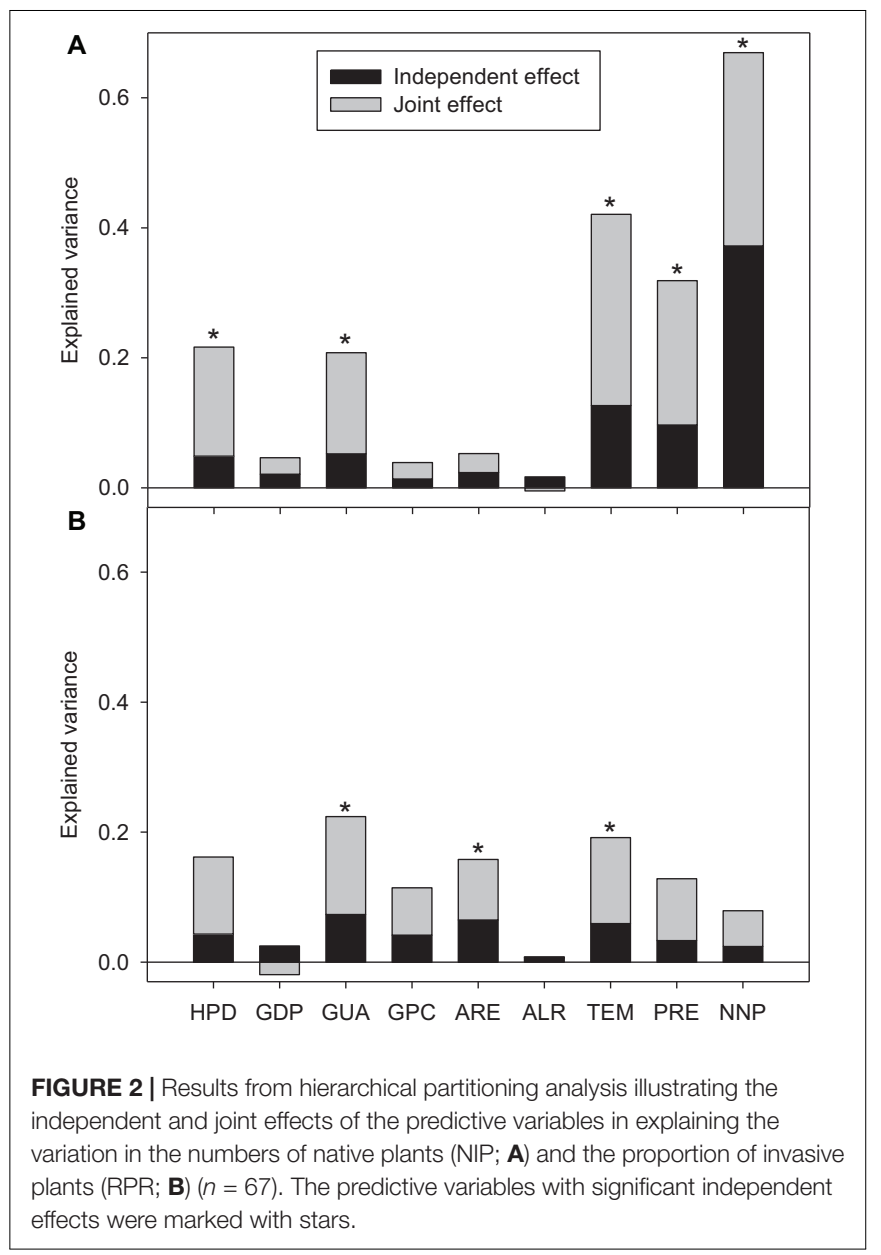

2017; Beaury et al., 2020). Our analyses provide useful clues about the efficient management of plant invasions in China's nature reserves. First, nature reserves in regions with rapid economic development and population increase should adopt robust and cost-efficient methods to prevent the introduction of invasive plant species. In recent decades, the human population and GPC in Eastern China have increased more rapidly than in the other regions (Zhang and Gao, 2019). Economic development may be associated with increased transportation between regions and enhanced disturbance of the local flora, which in turn translates to an increased number of propagules of invasive plants and a higher chance of establishment of invasive plant species (e.g., Guo et al., 2021). Second, nature reserves in regions characterized by a rapid temperature increase should be carefully evaluated and monitored as warming are critical for the establishment of invasive plants (Dawson et al., 2017; Roura-Pascual et al., 2021). A case study on subtropical nature reserves indicated that climate change mitigation and adaptation from policy and technology should be strengthened (Feng et al., 2020). Third, nature reserves with higher plant diversity should be paid more attention, since these localities may provide significantly high habitat heterogeneity, and provide more chance for invasive plants to colonize. 


\section{DATA AVAILABILITY STATEMENT}

The original contributions presented in the study are included in the article/Supplementary Material, further inquiries can be directed to the corresponding author/s.

\section{AUTHOR CONTRIBUTIONS}

All authors listed have made a substantial, direct and intellectual contribution to the work, and approved it for publication.

\section{FUNDING}

We would like to thank the financial support from the Special Foundation for National Science and Technology Basic Research Program of China (2019FY102000).

\section{REFERENCES}

Allen, J. A., Brown, C. S., and Stohlgren, T. J. (2009). Non-native plant invasions of United States National Parks. Biol. Invasions 11, 2195-2207. doi: 10.1007/ s10530-008-9376-1

Bai, F., Chisholm, R., Sang, W., and Dong, M. (2013). Spatial risk assessment of alien invasive plants in China. Environ. Sci. Technol. 47, 7624-7632. doi: $10.1021 /$ es400382c

Beaury, E. M., Finn, J. T., Corbin, J. D., Barr, V., and Bradley, B. A. (2020). Biotic resistance to invasion is ubiquitous across ecosystems of the United States. Ecol. Lett. 23, 476-482. doi: 10.1111/ele.13446

Blanchet, S., Leprieur, F., Beauchard, O., Staes, J., Oberdorff, Y., and Brosse, S. (2009). Broad-scale determinants of non-native fish species richness are context-dependent. Proc. R. Soc. B. 276, 2385-2394. doi: 10.1098/rspb.2009. 0156

Catford, J. A., Jansson, R., and Nilsson, C. (2009). Reducing redundancy in invasion ecology by integrating hypotheses into a single theoretical framework. Divers. Distrib. 15, 22-40. doi: 10.1111/j.1472-4642.2008.00521.x

Catford, J. A., Vesk, P. A., Richardson, D. M., and Pyšek, P. (2012). Quantifying levels of biological invasion: towards the objective classification of invaded and invasible ecosystems. Glob. Chang. Biol. 18, 44-62. doi: 10.1111/j.1365-2486. 2011.02549.x

Catford, J. A., Vesk, P. A., White, M. D., and Wintle, B. A. (2011). Hotspots of plant invasion predicted by propagule pressure and ecosystem characteristics. Divers. Distrib. 17, 1099-1110. doi: 10.1111/j.1472-4642.2011. 00794.x

Chen, S., Jiang, G., Ouyang, Z., Xu, W., and Xiao, Y. (2011). Relative importance of water, energy, and heterogeneity in determining regional pteridophyte and seed plant richness in China. J. Syst. Evol. 49, 95-107. doi: 10.1111/j.1759-6831. 2011.00120.x

Chytrı, M., Jarošík, V., Pyšek, P., Hájek, O., Knollová, I., Tich $\iota$, L., et al. (2008). Separating habitat invasibility by alien plants from the actual level of invasion. Ecology 89, 1541-1553. doi: 10.1890/07-0682.1

Davies, K. F., Chesson, P., Harrison, S., Inouye, B. D., Melbourne, B. A., and Rice, K. J. (2005). Spatial heterogeneity explains the scale dependence of the native-exotic diversity relationship. Ecology 86, 1602-1610. doi: 10.1890/041196

Dawson, W., Moser, D., van Kleunen, M., Kreft, H., Pergl, J., Pyšek, P., et al. (2017). Global hotspots and correlates of alien species richness across taxonomic groups. Nat. Ecol. Evol. 1:0186. doi: 10.1038/s41559-017-0186

Enders, M., Havemann, F., Ruland, F., Bernard-Verdier, M., Catford, J. A., GómezAparicio, L., et al. (2020). A conceptual map of invasion biology: integrating hypotheses into a consensus network. Glob. Ecol. Biogeogr. 28, 978-991. doi: 10.1111 /geb.13082

\section{ACKNOWLEDGMENTS}

We thank the scientists who did plant inventory in these nature reserves.

\section{SUPPLEMENTARY MATERIAL}

The Supplementary Material for this article can be found online at: https://www.frontiersin.org/articles/10.3389/fevo.2021. 655313/full\#supplementary-material

Supplementary Data Resource | References from which species lists of native and invasive seed plants of the 67 nature reserves were compiled.

Supplementary Table 1 | The coordinates, the number and the proportion of invasive plants in each of the 67 nature reserves.

Enders, M., Hütt, M.-T., and Jeschke, J. M. (2018). Drawing a map of invasion biology based on a network of hypotheses. Ecosphere 9:e02146. doi: 10.1002/ ecs2.2146

Essl, F., Dullinger, S., Rabitsch, W., Hulme, P. E., Hülber, K., Jarošík, V., et al. (2011). Socioeconomic legacy yields an invasion debt. Proc. Natl. Acad. Sci. U. S. A. 108, 203-207. doi: 10.1073/pnas.1011728108

Feng, B., Li, D., Zhang, Y., and Xue, Y. (2020). Evaluation on nature reserve management effectiveness of mitigation and adaptation on climate change: a case study of 12 typical nature reserves in Guangxi. Biodivers. Sci. 28, 10261035. doi: $10.17520 /$ biods.2019352

Foxcroft, L. C., Pyšek, P., Richardson, D. M., Genovesi, P., and MacFadyen, S. (2017). Plant invasion science in protected areas: progress and priorities. Biol. Invasions 19, 1353-1378. doi: 10.1007/s10530-016-1367-z

Fridley, J. D., Stachowicz, J. J., Naeem, S., Sax, D. F., Seabloom, E. W., Smith, M. D., et al. (2007). The invasion paradox: reconciling pattern and process in species invasions. Ecology 88, 3-17. doi: 10.1890/0012-9658(2007)88[3:tiprpa]2.0.co;2

Gantchoff, M. G., Wilton, C. M., and Belant, J. L. (2018). Factors influencing exotic species richness in Argentina's national parks. PeerJ. 6:e5514. doi: 10.7717/peerj. 5514

Guo, C. D., Zhu, J. F., Liu, X. Y., Zhao, C. Y., and Li, J. S. (2021). Contrasting biodiversity of invasive herbs inside and outside nature reserves in Guizhou. Biodivers. Sci. 29, 596-604. doi: 10.17520/biods.2020292

Hijmans, R. J., Cameron, S. E., Parra, J. L., Jones, P. G., and Jarvis, A. (2005). Very high resolution interpolated climate surfaces for global land areas. Int. J. Climatol. 25, 1965-1978. doi: 10.1002/joc.1276

Liu, J., Liang, S. C., Liu, F. H., Wang, R. Q., and Dong, M. (2005). Invasive alien plant species in China: regional distribution patterns. Divers. Distrib. 11, 341-347. doi: 10.1111/j.1366-9516.2005.00162.x

Lonsdale, W. M. (1999). Global patterns of plant invasions and the concept of invasibility. Ecology 80, 1522-1536. doi: 10.1890/0012-9658(1999)080[1522: gpopia]2.0.co;2

Luck, W. G. (2007). A review of the relationships between human population density and biodiversity. Biol. Rev. 82, 607-645. doi: 10.1111/j.1469-185x.2007. 00028.x

Melbourne, B. A., Cornell, H. V., Davies, K. F., Dugaw, C. J., Elmendorf, S., Freestone, A. L., et al. (2007). Invasion in a heterogeneous world: resistance, coexistence or hostile takeover? Ecol. Lett. 10, 77-94. doi: 10.1111/j.1461-0248. 2006.00987.x

Parker, I. M., Simberloff, D., Lonsdale, W. M., Goodell, K., Wonham, M., Kareiva, P. M., et al. (1999). Impact: toward a framework for understanding the ecological effects of invaders. Bio. Invasions 1, 3-19.

Pyšek, P., Hulme, P. E., Simberloff, D., Bacher, S., Blackburn, T. M., Carlton, J. T., et al. (2020). Scientists' warning on invasive alien species. Biol. Rev. 95, 1151-1534. doi: 10.1111/brv.12627 
Pyšek, P., Jarošík, V., Hulme, P. E., Kühn, I., Wild, J., Arianoutsou, M., et al. (2010). Disentangling the role of environmental and human pressures on biological invasions across Europe. P. Natl. Acad. Sci. U. S. A. 107, 12157-12162. doi: 10.1073/pnas.1002314107

Pyšek, P., Jarošík, V., Hulme, P. E., Pergl, J., Hejda, M., Schaffner, U., et al. (2012). A global assessment of invasive plant impacts on resident species, communities and ecosystems: the interaction of impact measures, invading species' traits and environment. Glob. Chang. Bio. 18, 1725-1737. doi: 10.1111/j.1365-2486.2011. 02636.x

Quinn, G. P., and Keough, M. J. (2002). Experimental Design and Data Analysis for Biologists. Cambridge: Cambridge University Press.

Rangel, T. F. L. V. B., Diniz-Filho, J. A. F., and Bini, L. M. (2010). SAM: a comprehensive application for spatial analysis in macroecology. Ecography 33, 46-50. doi: 10.1111/j.1600-0587.2009.06299.x

Roura-Pascual, N., Leung, B., Rabitsch, W., Rutting, L., Vervoort, J., Bacher, S., et al. (2021). Alternative futures for global biological invasions. Sustain. Sc. 16, 1637-1650. doi: 10.1007/s11625-021-00963-6

Sokal, R. R., and Rohlf, F. J. (1995). Biometry. New York: WH Freeman and Company.

Spear, D., Foxcroft, L. C., Bezuidenhout, H., and McGeoch, M. A. (2013). Human population density explains alien species richness in protected areas. Biol. Conserv. 159, 137-147. doi: 10.1016/j.biocon.2012.11.022

Stein, A., Gerstner, K., and Kreft, H. (2014). Environmental heterogeneity as a universal driver of species richness across taxa, biomes and spatial scales. Ecol. Lett. 17, 866-880. doi: 10.1111/ele.12277

Stohlgren, T. J., Jarnevich, C., Chong, G. W., and Evangelista, P. H. (2006). Scale and plant invasions: a theory of biotic acceptance. Preslia 78, 405-426.

Taylor, B. W., and Irwin, R. E. (2004). Linking economic activities to the distribution of exotic plants. P. Natl. Acad. Sci. U. S. A. 101, 17725-17730. doi: $10.1073 /$ pnas. 0405176101
Vilà, M., Basnou, C., Pyšek, P., Josefsson, M., Genovesi, P., Gollasch, S., et al. (2010). How well do we understand the impacts of alien species on ecosystem services? A pan-European, cross-taxa assessment. Front. Ecol. Environ. 8:135-144. doi: $10.2307 / 20696461$

Wu, S. H., Sun, H. T., Teng, Y. C., Rejmánek, M., Chaw, S. M., Yang, T. Y. A., et al. (2010). Patterns of plant invasions in China: taxonomic, biogeographic, climatic approaches and anthropogenic effects. Biol. Invasions 12, 2179-2206. doi: 10.1007/s10530-009-9620-3

Zhang, J., and Gao, J. (2019). Study on the problems and the countermeasures of the unbalanced development of regional economy in the 40 years of China's Reform and Opening up. Contemp. Econ. Manag. 41, 9-14.

Conflict of Interest: The authors declare that the research was conducted in the absence of any commercial or financial relationships that could be construed as a potential conflict of interest.

Publisher's Note: All claims expressed in this article are solely those of the authors and do not necessarily represent those of their affiliated organizations, or those of the publisher, the editors and the reviewers. Any product that may be evaluated in this article, or claim that may be made by its manufacturer, is not guaranteed or endorsed by the publisher.

Copyright (๑) 2021 Chen, Chen, Huang, Shao, Mao and Slik. This is an openaccess article distributed under the terms of the Creative Commons Attribution License (CC BY). The use, distribution or reproduction in other forums is permitted, provided the original author(s) and the copyright owner(s) are credited and that the original publication in this journal is cited, in accordance with accepted academic practice. No use, distribution or reproduction is permitted which does not comply with these terms. 